\title{
COMUNICAÇÃ̃o
}

\section{DESEMPENHO AGRONÔMICO DE MILHO CONSORCIADO COM FEIJÃO-DE-PORCO EM DUAS ÉPOCAS DE CULTIVO NO SISTEMA ORGÂNICO DE PRODUÇÃO}

\author{
Agronomic performance of corn intercropped with jack beans in two cropping \\ seasons in organic system
}

\author{
Adriano Perin¹, Janaína Tauil Bernardo², Ricardo Henrique Silva Santos ${ }^{3}$, Gilberto Bernardo de Freitas ${ }^{3}$
}

\begin{abstract}
RESUMO
Com o presente trabalho, avalia-se a produção de milho verde e grão em cultivo orgânico e a massa de leguminosa no consórcio milho, feijão-de-porco, em duas épocas de cultivo. Foram realizados dois experimentos de campo, em Viçosa (MG), no período de outono/inverno e de primavera/verão. O milho e o feijão-de-porco foram semeados simultaneamente na mesma linha, espaçadas de $1 \mathrm{~m}$. Os tratamentos foram as densidades de feijão-de-porco, $0,2,4$ e 6 plantas $\mathrm{m}^{-1}$ e as duas épocas de cultivo, no esquema fatorial 4 x 2 , utilizando-se o delineamento de blocos casualizados, com quatro repetições. A produção de milho foi influenciada somente pela época do ano, atingindo 7,26 e 9,64 Mg ha ${ }^{-1}$ de milho verde e 5,01 e 7,46 Mg ha ${ }^{-1}$ de grãos nos cultivos de outono/inverno e primavera/verão, respectivamente. Houve efeito significativo da densidade de plantas, da época de amostragem e da época de cultivo sobre a produção de massa do adubo verde. A maior produção de biomassa de feijão-de-porco (5,07 $\left.\mathrm{Mg} \mathrm{ha}^{-1}\right)$ foi obtida no final do ciclo do milho no cultivo de outono/inverno, com 4,8 plantas $\mathrm{m}^{-1}$. No cultivo de primavera/verão a produção máxima $\left(2,95 \mathrm{Mg} \mathrm{ha}^{-1}\right)$ foi obtida com 6 plantas $\mathrm{m}^{-1}$ também no final do ciclo da cultura do milho. Conclui-se que a produção de milho em cultivo orgânico não é prejudicada pela consorciação com feijão-de-porco.
\end{abstract}

Termos para indexação: Zea mays, Canavalia ensiformis, adubo verde, milho verde, milho grão.

\begin{abstract}
This work evaluates the yield of fresh and grain corn in organic system and the leguminous mass in the intercropping corn, jack beans, in two cropping seasons. Two field experiments were carried out in Viçosa (MG), on Autumn/Winter and Spring/Summer. Corn and jack beans were sown simultaneously in the same rows $1 \mathrm{~m}$ apart. The treatments were the jack beans density $(0,2,4$ or 6 plants $\mathrm{m}^{-1}$ ) and the two cropping season, arranged in a $4 \times 2$ factorial design and randomized blocks with four repetitions. The corn yield was influenced only by cropping season, reaching 7.26 and $9.64 \mathrm{Mg} \mathrm{ha}^{-1}$ of fresh and grain corn in Autumn/Winter season and 5.01 and $7.46 \mathrm{Mg} \mathrm{ha}^{-1}$ of fresh and grain corn in the Spring/Summer season. It was verified a significative effect of both plant density, sampling date and cropping season on the green manure mass production. The highest jack beans biomass yield $\left(5.07 \mathrm{Mg}^{-1}\right)$ was obtained at corn grain harvest stage on Autumn/Winter season, at 4.8 plants $\mathrm{m}^{-1}$. On the Spring/Winter season the highest yield (2.95 $\mathrm{Mg} \mathrm{ha}^{-1}$ ) was achieved with 6 plants $\mathrm{m}^{-1}$ also at corn grain harvest stage. It is concluded that the organic production of corn was not affected by the intercropping with jack beans.
\end{abstract}

Index terms: Zea mays, Canavalia ensiformis, green manure, corn ears, grain.

(Recebido em 10 de janeiro de 2006 e aprovado em 18 de abril de 2006)

A prática da adubação verde com leguminosas no sistema de produção orgânico é determinante para o aporte de $\mathrm{N}$ das culturas, tendo em vista que os fertilizantes normalmente utilizados contêm baixo teor de nitrogênio. As leguminosas apresentam sistema radicular _profundo e ramificado, permitindo maior extração e reciclagem de outros nutrientes, assim como melhor aproveitamento dos fertilizantes aplicados.

Resultados de pesquisas indicaram o grande potencial dos adubos verdes no fornecimento de nutrientes às culturas consorciadas (PERIN et al., 2004) e efeito favorável desta prática sobre características químicas do solo (HUNTER et al., 1995; OLIVEIRA, 1994) e rendimento das culturas (AITA et al., 2001; BORTOLINI et al., 2000; HEINRISCHS et al., 2001). No entanto, apesar dos grandes avanços científicos, principalmente na última década, no sentido de identificar os adubos verdes mais adequados à inclusão nos sistemas de produção, a compatibilização de seu cultivo na mesma área de culturas comerciais constitui-se ainda uma das principais limitações de seu uso pelos produtores (AMABILE, 1996; SKÓRA NETO, 1993), apontando a consorciação como

${ }^{1}$ Professor, CEFET Rio Verde - Rod. Sul Goiana, Km 01 - Cx. P. 66 - 75901-700 - Rio Verde/GO - perin@yahoo.com.br 2Engenheiro Agrônomo, Departamento de Fitotecnia/UFV - jana9573@yahoo.com.br

3Professor Adjunto, Departamento de Fitotecnia - Universidade Federal de Viçosa/UFV - Avenida P. H. Rolfs, s/no - 36570-000 - Viçosa, MG rsantos@ufv.br, bernardo@ufv.br 
prática promissora para minimizar a perda de renda dos agricultores.

Entre as leguminosas usadas para adubação verde, o feijão-de-porco (Canavalia eusiformis) é uma das mais propícias para o cultivo consorciado por suas características morfológicas e fisiológicas. Essa espécie possui ampla adaptação às condições de luz difusa (HENRICHS et al., 2002), possibilitando seu sombreamento parcial pela cultura principal e rápido crescimento inicial (ALVARENGA et al., 1995), o que dificultaria o estabelecimento de espécies invasoras pelo sombreamento.

Embora o cultivo intercalar de adubos verdes com as culturas de interesse econômico seja, em muitas situações, tecnicamente viável, existem poucos trabalhos com esta ênfase. Outros autores já pesquisaram o consórcio milho e feijão-de-porco, como Heinrichs et al. (2002). Esses autores estudaram quatro consórcios de milho com leguminosas e observaram que os efeitos positivos do feijão-de-porco na produção de grãos de milho foram significativos somente no segundo ano de adoção do cultivo consorciado. Os autores concluíram que a semeadura simultânea foi a prática mais recomendável, considerando-se a ausência de redução da produção de grãos de milho e a redução da operação pós-plantio. Skóra Neto (1993) avaliou, além do feijão-de-porco, sete leguminosas semeadas em três fases de desenvolvimento do milho com o objetivo de controlar plantas daninhas, concluindo que a consorciação de leguminosas com o milho tem a vantagem de diminuir a infestação de plantas daninhas no final do ciclo e no período após a colheita. Oliveira et al. (2003) avaliaram a produção de massa de milho verde em monocultivo e em dois consórcios, um com mucuna-preta e outro com feijão-de-porco. Verificouse com esse trabalho que não houve interferência das leguminosas sobre a produção e características agronômicas do milho. Também Alvarenga (2005) avaliou a sustentabilidade da produção de milho orgânico em sistema de produção intercalar com cinco espécies de adubos verdes, entre eles o feijão-de-porco. O autor observou que os adubos verdes constituíram fonte de nutrientes, com e sem controle de plantas daninhas concluindo, ainda, que nenhum dos adubos verdes promoveu aumento da produtividade do milho.

O trabalho de pesquisa teve como objetivo avaliar o efeito de épocas de cultivo e de diferentes densidades populacionais de feijão-de-porco, consorciado na mesma linha de semeadura, sobre o rendimento de milho em estádio verde e grãos maduros e sobre a produção de massa seca do feijão-de-porco.

O trabalho em campo, foi realizado durante os anos agrícolas 2001/02 e 2002/03, na área de produção orgânica da Horta de Pesquisa do Departamento de Fitotecnia da Universidade Federal de Viçosa, Viçosa (MG), Brasil, situado a $20^{\circ} 45^{\prime}$ sul e $42^{\circ} 51^{\prime}$ oeste. O solo do local é do tipo Cambissolo, e apresenta as seguintes características químicas $(0,0$ a $0,20 \mathrm{~m})$ : $\mathrm{pH}$ em $\mathrm{H}_{2} \mathrm{O}(1: 2,5)=5,3 ; \mathrm{Al}^{+3}=0,4$ cmol kg-1 $\mathrm{Ca}^{+2}=4,3 \mathrm{cmol} \mathrm{kg} \mathrm{kg}^{-1} ; \mathrm{Mg}^{+2}=1,1 \mathrm{cmol} \mathrm{kg}{ }^{-1} ; \mathrm{K}^{+}=$ $117 \mathrm{mg} \mathrm{kg}^{-1}$ e $\mathrm{P}$ disponível $=92,6 \mathrm{mg} \mathrm{kg}^{-1}$ de solo. A análise granulométrica da área experimental resultou em $13 \%$ areia grossa, $8 \%$ areia fina, $30 \%$ silte e $49 \%$ argila.

$\mathrm{O}$ delineamento experimental utilizado foi de blocos ao acaso, no esquema fatorial 4 x 2, com quatro repetições. Os tratamentos constaram de quatro densidades populacionais de feijão-de-porco, 0, 2, 4 e 6 plantas por metro de linha e duas épocas de cultivo, outono/inverno e primavera/verão. Cada parcela foi constituída por 6 linhas de $8 \mathrm{~m}$ de comprimento, com área de $48 \mathrm{~m}^{2}$, sendo considerada como parcela útil as quatro linhas centrais descontando-se borda de 1,0 m. O feijão-de-porco foi semeado no mesmo sulco e na mesma data de semeadura do milho.

Nos dois cultivos o solo foi preparado com grade pesada e gradagem leve. As sementes de milho 'AL 25 vencedor ${ }^{\circledR}$ ' e feijão-de-porco foram distribuídas manualmente, em sulcos espaçados de $1 \mathrm{~m}$, empregandose 7 sementes de milho e 4, 6 e 8 sementes de feijão-deporco por metro. Quinze dias após a emergência, a cultura do milho e do feijão-de-porco foram desbastadas para 5 plantas $\mathrm{m}^{-1}$ e 2 , 4, ou 6 plantas $\mathrm{m}^{-1}$, respectivamente. A adubação constituiu-se de $10 \mathrm{Mg} \mathrm{ha}^{-1}$ de massa seca de cama de aviário, cuja composição química encontra-se na Tabela 1, com $30 \%$ de água, distribuída no sulco de plantio.

TABELA 1 - Teor de nutrientes da cama de aviário utilizada como adubo orgânico no cultivo de milho. UFV, Viçosa MG, 2003.

\begin{tabular}{|c|c|c|c|c|c|c|c|c|c|c|}
\hline $\mathbf{N}$ & $\mathbf{P}$ & $\mathbf{K}$ & $\mathbf{C a}$ & Mg & $\mathbf{S}$ & Zn & $\mathbf{F e}$ & $\begin{array}{l}\text { Mn } \\
\mathrm{kg}^{-1}\end{array}$ & $\mathrm{Cu}$ & B \\
\hline 2,4 & 1,3 & 2,2 & 1,2 & 0,3 & 0,3 & 166 & 1851 & 212 & 28 & 26 \\
\hline
\end{tabular}

Ciênc. agrotec., Lavras, v. 31, n. 3, p. 903-908, maio/jun., 2007 
No cultivo de outono/inverno, irrigado por aspersão, a semeadura ocorreu em 15 de março de 2002, com colheita de milho verde ( $75 \%$ água) em 2 de julho de 2002 e colheita de milho grão em 4 de setembro de 2002. O controle mecânico de plantas invasoras foi realizado aos 35 dias após o plantio (DAP). No cultivo de primavera/ verão, sem irrigação, a semeadura ocorreu em 18 de outubro de 2002, com colheita de milho verde em 10 de janeiro de 2003 e de milho grão em 19 de março de 2003.

No estádio de milho verde e no final do ciclo da cultura do milho, em dois locais escolhidos ao acaso em cada parcela útil, as plantas de feijão-de-porco presentes em $1 \mathrm{~m}^{2}$ foram cortadas rente ao solo e determinada a produção de massa de matéria fresca. Retirou-se uma subamostra de aproximadamente $250 \mathrm{~g}$ de massa fresca de cada parcela, que foi pesada e colocada em estufa de ventilação forçada de ar a $65^{\circ} \mathrm{C}$, até atingir massa constante, para quantificar a produção de massa de massa seca de parte aérea. Em 2,0 $\mathrm{m}^{2}$ de cada parcela, na colheita do milho verde foram avaliados o rendimento $\left(\mathrm{Mg} \mathrm{ha}^{-1}\right)$, comprimento $(\mathrm{cm})$, diâmetro $(\mathrm{cm})$ e massa das espigas $(\mathrm{g})$, enquanto que na colheita dos grãos foram determinadas a produtividade $\left(\mathrm{Mg} \mathrm{ha}^{-1}\right)$ e o número de espigas por planta. Os dados foram submetidos à análise de variância adotando-se teste $\mathrm{F}$ a $5 \%$ de probabilidade, com auxílio do SAEG versão 8.0.

A produção de milho foi influenciada somente pela época de cultivo, verificando-se os melhores desempenhos tanto da produção de milho verde quanto da produção de milho grão no cultivo de primavera/verão (Tabela 2). $\mathrm{O}$ cultivo de até seis plantas de feijão-de-porco por metro não afetou o desempenho de milho verde ou grãos, tanto no outono/inverno como na primavera/verão e os valores médios finais obtidos constam da Tabela 2. Isso indica que, até a densidade populacional avaliada, a interferência entre essas duas culturas não ocasiona prejuízo à produtividade do milho. Estes resultados divergem, no entanto, dos obtidos por Skóra Neto (1993) que observou menores rendimentos do milho consorciado com feijãode-porco em plantio simultâneo, comparado ao milho solteiro. No cultivo de primavera/verão as plantas apresentaram tanto maior número de espigas, quanto espigas com maior diâmetro, sem prejuízo do comprimento, sempre maior que $15,0 \mathrm{~cm}$. Esses aspectos são importantes para a comercialização de milho verde, uma vez que comercializa-se a produção por unidade de espiga e o maior diâmetro das mesmas é atrativo para a compra.

No cultivo de primavera/verão, o rendimento de massa de matéria seca do feijão-de-porco amostrado em estádio de milho verde, apresentou comportamento quadrático, atingindo máxima produção de biomassa $\left(1,39 \mathrm{Mg} \mathrm{ha}^{-1}\right)$ na densidade de 4,4 plantas $\mathrm{m}^{-1}$ (Figura 1). Nesta fase, a competição entre o milho e feijão-de-porco por recursos naturais, pode ter sido limitante à segunda espécie na expressão de sua máxima produção de massa, já que o milho apresenta maior taxa inicial de crescimento. Na colheita do milho grão, a massa seca produzida pelo feijão-de-porco apresentou comportamento linear crescente com o aumento do número de plantas (Figura 1). Provavelmente, o aumento da disponibilidade de recursos com a maturação e senescência de milho, passou a amenizar as limitações ao crescimento, permitindo que o adubo verde pudesse responder em massa ao aumento no número de plantas.

TABELA 2 - Número, comprimento, massa e diâmetro das espigas em estado verde, e rendimento de milho verde e grãos no outono/inverno e primavera/verão, em cultivo orgânico. UFV, Viçosa - MG, 2003

\begin{tabular}{lcccccc}
\hline $\begin{array}{c}\text { Época } \\
\text { De cultivo }\end{array}$ & $\begin{array}{c}\text { Comprimento } \\
(\mathbf{c m})\end{array}$ & $\begin{array}{c}\text { Diâmetro } \\
(\mathbf{c m})\end{array}$ & $\begin{array}{c}\text { Peso } \\
\left(\mathbf{g ~ e s p i g a}^{-1}\right)\end{array}$ & $\begin{array}{c}\text { Rendimento } \\
\left(\mathbf{M g ~ h a}^{-1}\right)\end{array}$ & $\begin{array}{c}\text { Milho verde } \\
\text { Esplanta } \\
\left(\mathbf{n}^{\mathbf{0}}\right)\end{array}$ & $\begin{array}{c}\text { Rendimento } \\
\left(\mathbf{M g ~ h a}^{-1}\right)\end{array}$ \\
\hline Outono/inverno & $15,69 \mathrm{a}$ & $4,13 \mathrm{~b}$ & $132,04 \mathrm{~b}$ & $7,26 \mathrm{~b}$ & $1,10 \mathrm{~b}$ & $5,01 \mathrm{~b}$ \\
Primavera/verão & $15,75 \mathrm{a}$ & $6,11 \mathrm{a}$ & $148,30 \mathrm{a}$ & $9,64 \mathrm{a}$ & $1,33 \mathrm{a}$ & $7,46 \mathrm{a}$ \\
\hline Média & 15,72 & 5,12 & 140,17 & 8,45 & 1,22 & 6,24 \\
\hline
\end{tabular}

Na comparação entre épocas de cultivo, em cada coluna letras minúsculas distintas representam diferenças significativas entre tratamentos submetidos ao teste $\mathrm{F}$ a $5 \%$ de probabilidade. 
Em termos práticos, o comportamento apresentado pelo feijão-de-porco tem implicações benéficas. No período de maior crescimento do milho, o adubo verde encontra condições limitantes ao seu crescimento e, dessa forma, os riscos de competição com o milho por recursos edáficos são atenuados. Quando é amenizada a condição limitante ao feijão-de-porco, o milho já não mais apresenta riscos de receber competição, visto encontrar-se em estádio de maturação fisiológica de seus grãos. Heinrisch et al. (2002) salientaram que o cultivo intercalar do feijão-de-porco não atrapalha a colheita mecânica do milho, já que esse adubo verde apresenta hábito de crescimento prostrado. Vale ressaltar que no presente trabalho a semeadura no mesmo sulco facilitou as operações de capina e conseqüentemente reduziu o tempo disponibilizado nessas operações, constituindo-se essa uma das principais dificuldades operacionais de lavouras consorciadas.

No outono/inverno, o milho não encontrou as mesmas condições ao seu crescimento e isso permitiu que a massa de matéria seca do adubo verde incrementasse com o aumento no número de plantas, já na fase de milho verde (Figura 2). Porém, o comportamento apresentado pelo feijão-de-porco não comprometeu a produção de milho verde ou grãos, visto não ter sido detectado efeitos nessas variáveis. $\mathrm{O}$ efeito quadrático na produção de massa de matéria seca do feijão-de-porco colhido na fase de milho grão, com máximo rendimento $\left(5,44 \mathrm{Mg} \mathrm{ha}^{-1}\right)$ na densidade de 4,8 plantas $\mathrm{m}^{-1}$ (Figura 2) é próximo à produção obtida em seu cultivo isolado $\left(6,82 \mathrm{Mg} \mathrm{ha}^{-1}\right)$.

Carvalho (1984) e Heinrisch et al. (2002) verificaram que o feijão-de-porco semeado simultaneamente ao milho, conferiu maior rendimento massa de 1.000 grãos, quando comparado ao monocultivo de milho. Alvarenga (2005) avaliou, em trabalho para sustentabilidade da produção de milho orgânico, que os adubos verdes intercalados constituíram fontes de nutrientes, com ou sem controle de plantas daninhas. Spagnollo et al. (2002) também evidenciaram maior rendimento de milho, sob cultivo intercalar por dois anos aos adubos verdes feijão-deporco, mucuna cinza, guandu anão e soja preta, comparativamente ao milho em cultivo isolado. Os autores reportaram que a resposta é devida ao aporte de nitrogênio pelos adubos verdes.

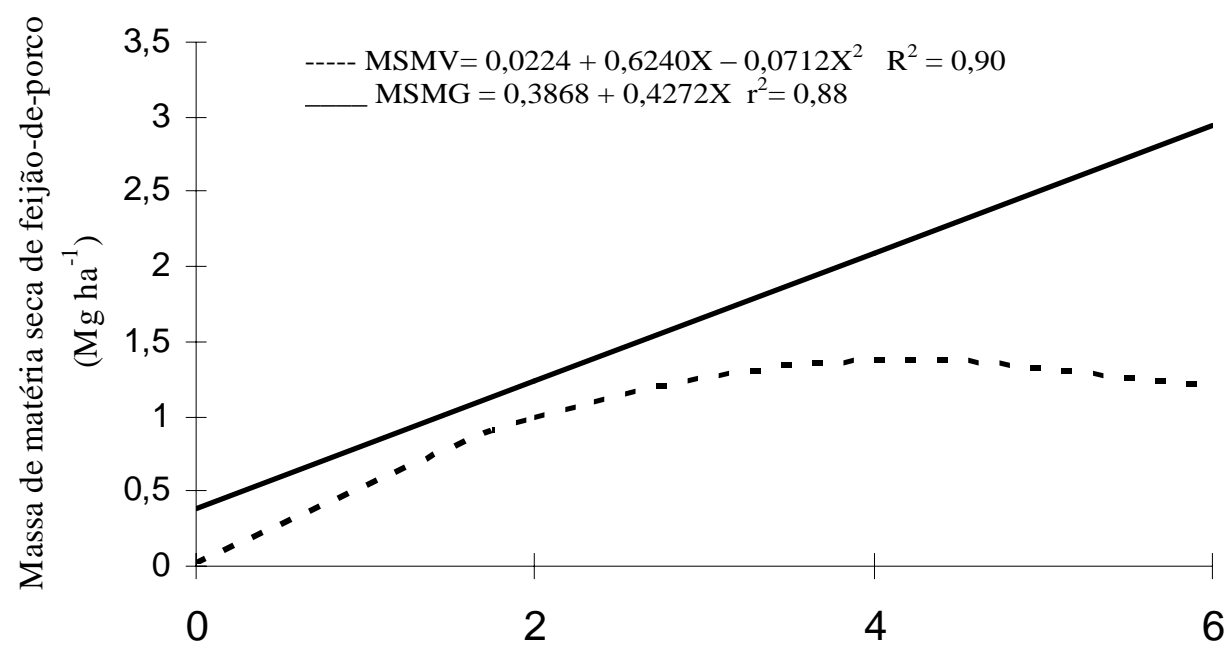

Plantas de feijão-de-porco $\mathrm{m}^{-1}$ linear

FIGURA 1 - Produção de massa de matéria seca do feijão-de-porco consorciado em diferentes densidades populacionais com milho e corte no estádio de milho verde (MSMV) ou grãos maduros (MSMG), no cultivo de de primavera/verão. UFV, Viçosa-MG, 2003.

Ciênc. agrotec., Lavras, v. 31, n. 3, p. 903-908, maio/jun., 2007 


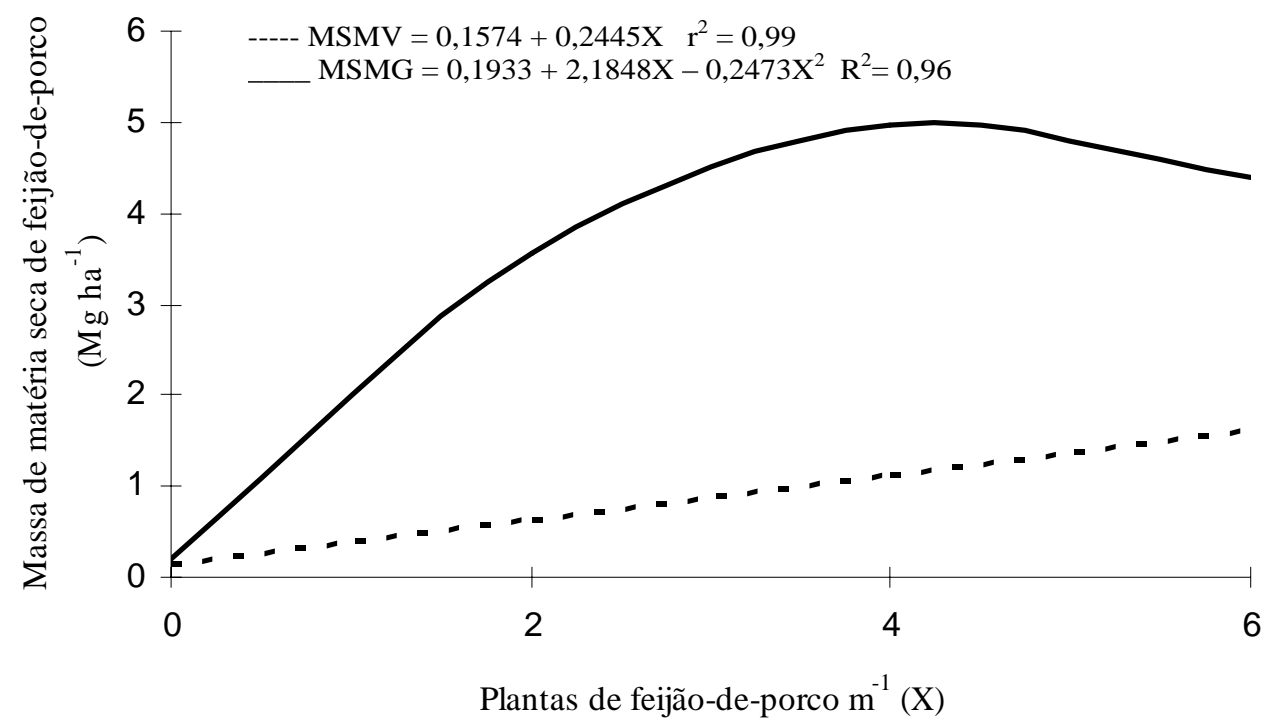

FIGURA 2 - Produção de massa de matéria seca de feijão-de-porco consorciado em diferentes densidades populacionais com milho e corte no estádio de milho verde (MSMV) ou grãos maduros (MSMG), no cultivo de outono/inverno. concluir:

Em função dos resultados alcançados, pode-se

O consórcio de feijão-de-porco e milho, quando semeados na mesma linha simultaneamente, não afeta a produção de milho verde e milho grão, no sistema de produção orgânica.

Quando consorciado com feijão-de-porco, tanto a cultura de milho verde quanto de milho grão apresentam maior desempenho no cultivo de primavera/verão do que no cultivo de outono/inverno, no sistema orgânico de produção.

A produção de massa de matéria seca de feijão-deporco consorciado com milho em sistema orgânico de produção é maior no cultivo de outono/inverno do que no cultivo de primavera/verão.

\section{REFERÊNCIAS BIBLIOGRÁFICAS}

AITA, C.; BASSO, C. J.; CERETTA, C. A.; GONÇALVES, C. N.; DAROS, C. O. Plantas de cobertura de solo como fonte de nitrogênio ao milho. Revista Brasileira de Ciência do Solo, Viçosa, v. 25, n. 1, p. 157-165, jan./mar. 2001.

ALVARENGA, R. C. Adubação verde intercalar como fonte de nutrientes para a cultura do milho orgânico. Disponível em: 〈http://www.planetaorganico.com.br/trabmilho1.htm>. Acesso em: 7 nov. 2005.
ALVARENGA, R. C.; COSTA, L. M.; MOURA FILHO, W.; REGAZZI, A. J. Características de adubos verdes de interesse para a conservação e recuperação de solos. Pesquisa Agropecuária Brasileira, Brasília, v. 30, n. 2, p. 175-185, 1995.

AMABILE, R. F. Comportamento de adubos verdes e épocas de semeadura nos Cerrados do Brasil Central. 1996. 123 f. Dissertação (Mestrado em Fitotecnia) Escola Superior de Agricultura Luiz de Queiroz, Piracicaba, 1996.

BORTOLINI, C. G.; SILVA, P. R.; ARGENTA, G. Sistemas consorciados de aveia preta e ervilhaca comum como cobertura de solo e seus efeitos na cultura do milho em sucessão. Revista Brasileira de Ciência do Solo, Viçosa, v. 24, n. 3, p. 897-903, jul./set. 2000.

CARVALHO, S. C. de. Produção de hortigranjeiros em rotação e consorciação. In: FUNDAÇÃO CARGILL. A adubação no Brasil. Campinas, 1984. p. 222-231.

HEINRICHS, R.; AITA, C.; AMADO, T. J. C.; FANCELLI, A. L. Cultivo consorciado de aveia e ervilhaca: relação $\mathrm{C} / \mathrm{N}$ da fitomassa e produtividade do milho em sucessão. Revista Brasileira de Ciência do Solo, Viçosa, v. 25, n. 2, p. 331340, abr./jun. 2001. 
HEINRICHS, R.; VITTI, G. C.; MOREIRA, A.; FANCELLI, A. L. Produção e estado nutricional do milho em cultivo consorciado intercalar com adubos verdes. Revista Brasileira de Ciência do Solo, Viçosa, v. 26, n. 1, p. 225230, jan./mar. 2002.

HUNTER, D. J.; YAPA, L. G. G.; HUE, N. V.; EAQUB, M. Comparative effects of green manure and lime on the growth of sweet corn and chemical properties of an acid oxisol in Western Samoa. Communication Soil Science and Plant Analysis, New York, v. 26, n. 1, p. 375-388, 1995.

OLIVEIRA, E. L. de. Coberturas verdes de inverno em adubação nitrogenada em algodoeiro. Revista Brasileira de Ciência do Solo, Viçosa, v. 18, n. 1, p. 235241, jan./mar. 1994.

OLIVEIRA, T. K. de; CARVALHO, G. J. de; MORAES, R. N. de S.; MAGALHÃES JÚNIOR, P. R. Características agronômicas e produção de fitomassa de milho verde em monocultivo e consorciado com leguminosas.
Ciência e Agrotecnologia, Lavras, v. 27, n. 1, p. 223-227, jan./fev. 2003.

PERIN, A.; SANTOS, R. H. S.; URQUIAGA, S.; GUERRA, J. G. M.; CECON, P. R. Efeito residual da adubação verde no rendimento de brócolo (Brassica oleraceae L. var. italica) cultivado em sucessão ao milho (Zea mays L.). Ciência Rural, Santa Maria, v. 34, n. 6, p. 1739-1745, nov./ dez. 2004.

SKÓRA NETO, F. Controle de plantas daninhas através de coberturas verdes consorciadas com milho. Pesquisa Agropecuária Brasileira, Brasília, v. 28, n. 10, p. 11651171, out. 1993.

SPAGNOLLO, E.; BAYER, C.; WILDNER, L. P.; ERNANI, P. R.; ALBUQUERQUE, J. A.; PROENÇA, M. M. Leguminosas estivais intercalares como fonte de nitrogênio para o milho, no Sul do Brasil. Revista Brasileira de Ciência do Solo, Viçosa, v. 26, n. 2, p. 417423, abr./jun. 2002. 